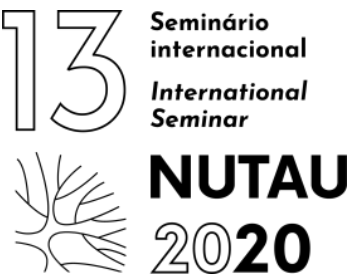

\title{
Gestão de resíduos de podas na Cidade Universitária Armando de Salles Oliveira (CUASO) - USP
}

\author{
Aline Macedo Mellucci ${ }^{1}$, Daniella Vilela Lima², Hermes Fajersztajn ${ }^{3}$ \\ ${ }^{1}$ Universidade de São Paulo, Especialista em Gestão e Tec. Ambientais, aline.mellucci@usp.br \\ 2Universidade de São Paulo, Doutora em Ciências, daniellavilela@usp.br \\ 3Universidade de São Paulo, Doutor em Engenharia de Construção Civil e Urbana hfajer@usp.br
}

\begin{abstract}
RESUMO: A Prefeitura do Campus USP da Capital (PUSP-C) é a unidade da Universidade de São Paulo (USP) que realiza a gestão dos resíduos sólidos urbanos e das áreas verdes, na Cidade Universitária Armando de Salles Oliveira (CUASO), utilizando da metodologia do PDCA. No período de junho/2018 a junho/2019 os restos vegetais, provenientes de corte de grama, podas e supressões de exemplares arbóreos, foram destinados a reaproveitamento nas seguintes quantidades aproximadas: (1) $1.170 \mathrm{~m}^{3}$ para geração de energia; (2) 100 $\mathrm{m}^{3}$ /ano para compostagem no viveiro de mudas da PUSP-C(composto utilizado nas áreas ajardinadas do Campus)e (3) $1 \mathrm{~m}^{3} / \mathrm{mês}$ é doado para um projeto de cunho socioambiental da comunidade do entorno do Campus. Outra destinação, que ainda não é quantificada, é o fornecimento de fatias de troncos à comunidade USP, para uso em artesanatos e confecção de objetos diversos. A gestão dos resíduos arbóreos deve ser eficiente na sua destinação, possibilitando beneficiar ao máximo esse produto. Reutilizar é prolongar a vida útil dos materias, em sua função original ou adaptada. Propiciar a transformação dos resíduos vegetais da CUASO, não é só reutilizar, mas abrilhantar o valor desse resíduo.
\end{abstract}

\section{PALAVRAS-CHAVE: resíduos, arborização, sustentabilidade}

\begin{abstract}
The Prefecture of the University of São Paulo Capital Campus (PUSP-C) is the University's unit reponsible for performing the management of green urban areas and solid waste in the "Cidade Universitária Armando de Salles Oliveira (CUASO)", by using PDCA methodology. From June 2018 to June 2019, plant residues, from cutting grass, pruning and tree removal, were destined in the following approximate volumes: (1) $1,170 \mathrm{~m}^{3} /$ year for energy generation; (2) $100 \mathrm{~m}^{3} /$ year for composting in the PUSP-C seedling nursery (compost used in campus garden areas) and (4) $1 \mathrm{~m}^{3} /$ month was donated to a socioenvironmental project of the community surrounding campus. Another destination, which has not yet been quantified, is the supply of slices of trees trunks to the university community, for handicrafts and for making various objects. The management of urban forest waste must be efficient also in regard to destination, making it possible to burnish or reuse most of this product. To reuse is to prolong the life cycle of the materials, in their original or adapted function. Creating this possibility of transformation to urban forest waste is not only reusing, but enhancing the value of that waste.
\end{abstract}

KEYWORDS: waste, urban forest, sustainability

\section{INTRODUÇÃO}

O Gerenciamento dos Resíduos Sólidos Urbanos $(\mathrm{RSU})^{1}$ é um desafio constante nas grandes cidades está diretamente relacionado ao saneamento básico e à saúde pública, tendo potencial de impactar o solo, o ar e a água. Sendo assim, o manejo dos RSU e a destinação final ambientalmente adequada ${ }^{2}$, bem como a disposição final ambientalmente adequada $^{3}$ dos rejeitos em aterros sanitários, são indissociáveis à qualidade de vida da população e indispensáveis à conservação dos recursos naturais e à proteção do meio ambiente (Brasil, 2020).

A gestão integrada de resíduos ${ }^{4}$ é a forma mais eficiente de realizar a destinação final ambientalmente adequada de cada tipo de resíduo. E nesse processo, pode-se considerar diversas possibilidades de transformação dos resíduos passíveis de reciclagem, tais como insumos ou novos produtos.

A Prefeitura do Campus USP da Capital (PUSP-C) é o órgão que realiza a gestão do campus Cidade Universitária Armando de Salles Oliveira (CUASO), provendo serviços de infraestrutura e 
manutenção e viabilizando o funcionamento da Universidade de São Paulo como instituição de pesquisa, ensino e extensão.

A Divisão Técnica de Gestão Socioambiental (DVGS) é a área que integra a gestão dos RSU e a manutenção das áreas verdes, garantindo a destinação final ambientalmente adequada dos resíduos de poda da CUASO.

Apresentamos neste trabalho o processo de tratamento dos resíduos de poda da CUASO, que representam uma parcela cujos dados referem-se ao período de junho de 2018 a junho de 2019.

O objetivo principal da PUSP-C com o manejo dos resíduos de poda na CUASO é garantir:

- a destinação final ambientalmente adequada desses resíduos;

- o aproveitamento dos resíduos com potencial energético e de matéria-prima;

- a melhoria contínua no modelo de gestão;

- a redução de impactos ambientais e de custos financeiros.

\section{A GESTÃO DE RESÍDUOS DE PODA NA CUASO}

A CUASO possui $924.836 \mathrm{~m}^{2}$ de áreas comuns verdes e ajardinadas, aproximadamente 33.000 árvores e mais de 10 hectares de reservas ecológicas (Prefeitura do Campus da Capital, 2020). Antes de 2010, o processo utilizado pela PUSP-C para a destinação dos resíduos de poda no campus era pouco desenvolvido, na maioria das vezes eram descartados em áreas internas menos visíveis (o que demandava grandes espaços), para ir se decompondo com o tempo. Parte desse material também era removido para os aterros sanitários.

No município de São Paulo a Lei13.478/2002 caracteriza como "grande gerador" a pessoa jurídica cuja geração diária de RSU é superior a 200 litros (São Paulo, 2002). E por estar categorizada como grande geradora, a Universidade de São Paulo tem a responsabilidade legal de gerenciamento de seus próprios resíduos, desde a coleta, transporte, tratamento até a destinação final.

Com a instituição da Política Nacional de Resíduos Sólidos (Lei 12.305/2010), houve a necessidade da construção de procedimentos mais sustentáveis, ascendendo para os sistemas de gerenciamento de resíduos, assim como a gestão integrada e mais eficiente de resíduos sólidos.

Nesse contexto a PUSP-C reformulou a sua estrutura organizacional em 2011 e criou a Divisão Técnica de Gestão Socioambiental (DVGS), na qual estão inseridos os Serviços Técnicos de Gestão de Resíduos e Recursos Naturais (SVRN), de Saúde Ambiental (SVSA) e de Gestão Ambiental (SVGA), com o objetivo de promover a sustentabilidade ambiental no campus.
O Serviço Técnico de Gestão de Resíduos (SVRN) é responsável pelo gerenciamento dos resíduos perigosos e não perigosos na CUASO, bem como auxilia a gestão compartilhada de alguns tipos de resíduos nos demais campi e prefeituras. No que tange ao ensino e à pesquisa, o SVRN realiza campanhas de capacitação funcional e educação ambiental, assim como assessora professores e orientandos com dados para pesquisas na pósgraduação e em disciplinas de Graduação e trabalhos de conclusão de cursos (TCCs).

Mais especificamente, sobre o assunto abordado, o serviço de coleta e destinação dos resíduos de poda realizado pelo SVRN nas áreas comuns do campus consiste na instalação de caçambas de $30 \mathrm{~m}^{3}$ na CUASO, e posteriormente quando estão carregadas com o resíduo, a coleta é executada e como destinação final são beneficiadas em cavacos de madeira para geração de energia.

Esse serviço também é realizado na Escola de Artes, Ciências e Humanidades (EACH), com caçambas de $30 \mathrm{~m}^{3}$ e no Quadrilátero da Saúde e do Direito (QSD), com caçambas de $5 \mathrm{~m}^{3}$, nesse último, o volume da caçamba é menor devido à falta de espaço físico para acomodá-las no local. Esse serviço foi estendido às Unidades da CUASO, da EACH e ao QSD tendo como foco a sustentabilidade e a melhoria contínua no processo de gestão compartilhada, a minimização dos impactos administrativos, ambientais e de custos financeiros. Nesse modelo compartilhado, o serviço é cotratado pela PUSP-C, apresentando em seu edital, o memorial descritivo, que abarca todas as etapas do manejo desse resíduo, de forma que todos os resíduos de podas realizadas pelas unidades participantes desse edital têm a mesma destinação, isto é, os resíduos de podas são encaminhados para geração de energia - uma destinação final ambientalmente adequada e aproveitável.

Uma vez que o serviço contratado no modelo compartilhado tem um grande volume de caçambas utilizadas, o custo por unidade teve uma redução de custos de 38,83\%; ademais, várias etapas administrativas e de insumos, foram poupadas. Contudo, os dados tratados nesse trabalho, referemse unicamente aos resíduos de podas das áreas comuns da CUASO.

O manejo dos resíduos de poda, bem como a destinação ambientalmente adequada para este tipo de resíduo, é uma demanda do Serviço Técnico de Gestão Ambiental (SVGA), cuja finalidade é a manutenção das áreas verdes ajardinadas do campus, que envolve o corte da grama, a poda, a remoção de exemplares arbóreos e o plantio compensatório.

Na CUASO é grande a geração de resíduos de poda, que são resultantes das seguintes 
necessidades: limpeza (retirada de galhos secos, senis ou mortos); correção (remoção de partes que comprometem a estabilidade arbórea); adequação, (retirada de partes próximas da fiação elétrica, iluminação ou no campo de visão das câmeras de segurança); levantamento (retirada das partes que impedem a livre circulação de pessoas ou veículos); atendimento emergencial (remoção de galhos que se quebram por tempestades, chuvas ou por ataque por pragas urbanas).

Toda poda ou supressão de exemplar arbóreo na CUASO é realizada em conformidade com as autorizações emitidas pela Secretaria Municipal do Verde e do Meio Ambiente (SVMA) e de acordo com o Manual Técnico de Podas de Árvores do Município de São Paulo.

O SVGA possui equipe própria dedicada à manutenção da área verde da PUSP-C (jardins, podas e remoções emergenciais) e à produção de mudas no viveiro (plantio compensatório das árvores caídas/suprimidas ou atendimento a Termos de Compromisso Ambiental - TCA). Os restos vegetais originários dessas atividades são gerenciados pelo SVRN e são desses resíduos os dados apresentados neste trabalho.

As áreas de uso comum do campus (ruas, avenidas, calçadas, praças e jardins) são divididas em quatro setores cuja manutenção das áreas verdes é realizada por empresas contratadas, que são responsáveis pela remoção dos restos vegetais oriundos da sua atividade.

Algumas dessas empresas utilizam a mesma empresa contratada pela PUSP-C para a destinação dos resíduos de poda.

\section{METODOLOGIA}

A gestão dos resíduos arbóreos deve ser eficiente na sua destinação, possibilitando beneficiar ao máximo esse material, considerando os tipos de utilização, o valor agregado e a cadeia produtiva em que pode ser absorvido.

E pensando sempre nessa lógica e dinâmica fluida, a metodologia escolhida para executar a gestão dos RSUs da CUASO, nos quais se incluem os resíduos de poda, tem com eixo central o ciclo do PDCA (do inglês "plan", "do", "check" e "act") (ABNT, 2004), embasado sempre no diagnóstico de geração e fluxo dos resíduo com foco em novos processos e alternativas tecnológicas para coletar, tratar e reciclar os resíduos sólidos tendo como meta a minimização, a reutilização e a reciclagem dos resíduos (Figura 1)

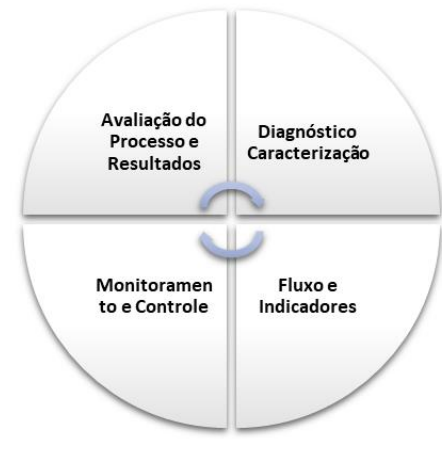

Figura 1: PDCA, (Mellucci/2020).

Uma das etapas do PDCA é a avaliação do processo e seus resultados, e dentro dessa premissa, avaliar o processo, assim como todos os acontecimentos surgidos durante o caminho, permite-nos a possibilidade de traçar novas estratégias e metas de melhoria, tanto na eficiência do sistema como também trazendo a possibilidade de inovação, de criação, de ousar em outras direções.

Nesse contexto, o processo empregado tem como eixo central o tripé da sustentabilidade, que considera os pilares ambiental, social e financeiro. Para se atingir esse modelo, o processo de destinação é dinâmico, à medida que surgem oportunidades de aproveitamento desse material (Figura 2).

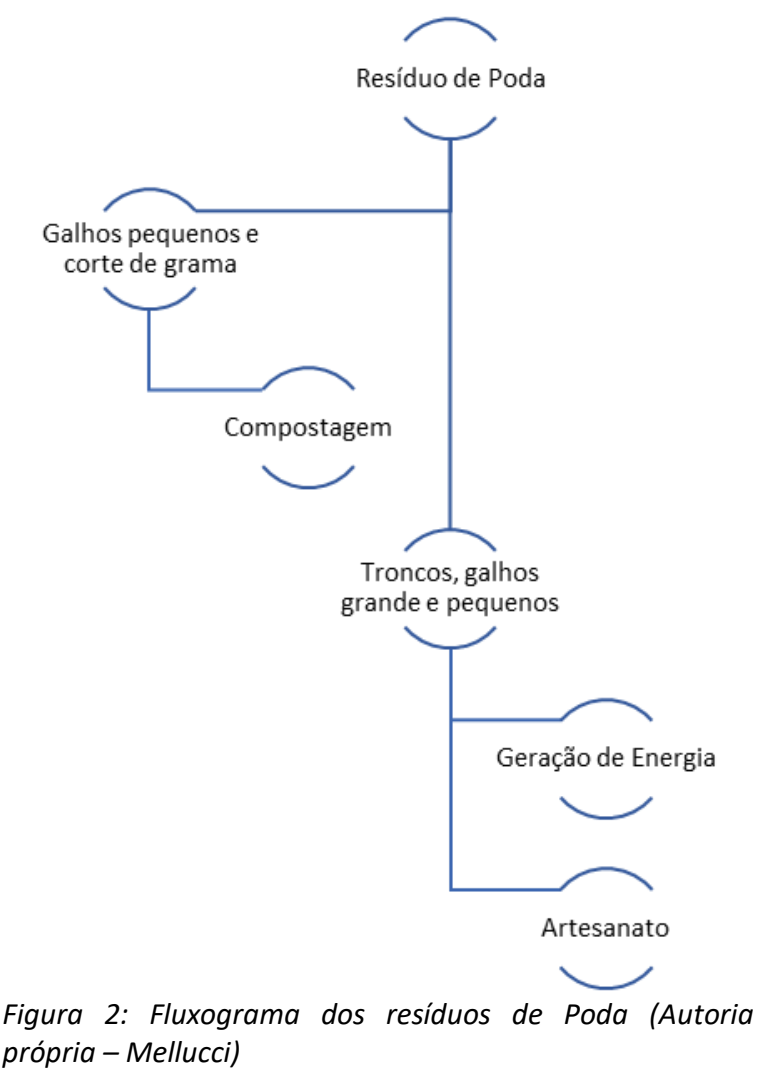




\section{RESULTADOS E DISCUSSÃO}

Os dados utilizados neste trabalho referemse ao contrato no $00013 / 2018$ - PUSP-C, que teve início em junho de 2018 e se encerrou em junho de 2019. Neste período foram destinados para geração de energia cerca de $1.170 \mathrm{~m}^{3}$ de restos vegetais, encaminhados em 39 caçambas de $30 \mathrm{~m}^{3}$ cada.

A estimativa anual para a destinação desse material é de 48 caçambas de $30 \mathrm{~m}^{3}$ para as atividades da equipe do viveiro de mudas da PUSP-C. A quantidade de caçambas utilizadas depende da sazonalidade e das intempéries, em alguns anos utiliza-se a totalidade, em outros não.

O maior fluxo de destinação dos restos vegetais direciona-se para a empresa recicladora Made Vila Bioenergia, que faz o processo de picotagem dos galhos e troncos, que após passarem por período de secagem resultam nos cavacos de madeira reciclada, que possuem alto poder calorífico. Os cavacos são vendidos a outras empresas, reduzindo a demanda de consumo de outros combustíveis para alimentar caldeiras (Figura 3).

Cerca de $100 \mathrm{~m}^{3}$ /ano dos restos vegetais, resultantes do corte de grama e manutenção de jardins, são compostados pela equipe do SVGA na área do viveiro de mudas da PUSP-C. O composto resultante desse processo é utilizado para a manutenção das áreas ajardinadas da CUASO e na produção de vasos.

$\mathrm{O}$ processo de compostagem realizado no viveiro de mudas da PUSP-C poderia ser mais bem explorado, contudo, dispomos de uma equipe reduzida de funcionários, o que dificulta ampliar e tornar a composteira mais eficiente.

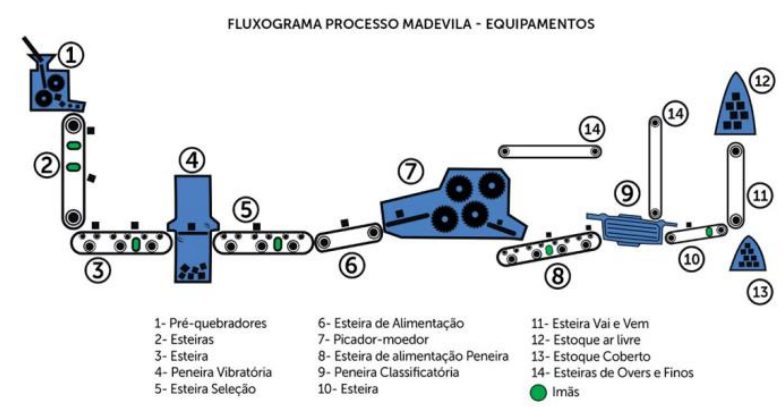

Figura 3: Fluxogramada empresa Made Vila.

Em menor escala, uma quantidade aproximada de $1 \mathrm{~m}^{3} /$ mês de picotes de galhos é doada para um projeto de cunho socioambiental, criado por um grupo denominado Coletivo das Vilas Beatriz, Ida e Jataí-Ecobairros (Figura 4). O projeto tem como proposta a compostagem comunitária em praças, com a participação de moradores do bairro, que contribuem com resíduos e no manejo semanal das composteiras.

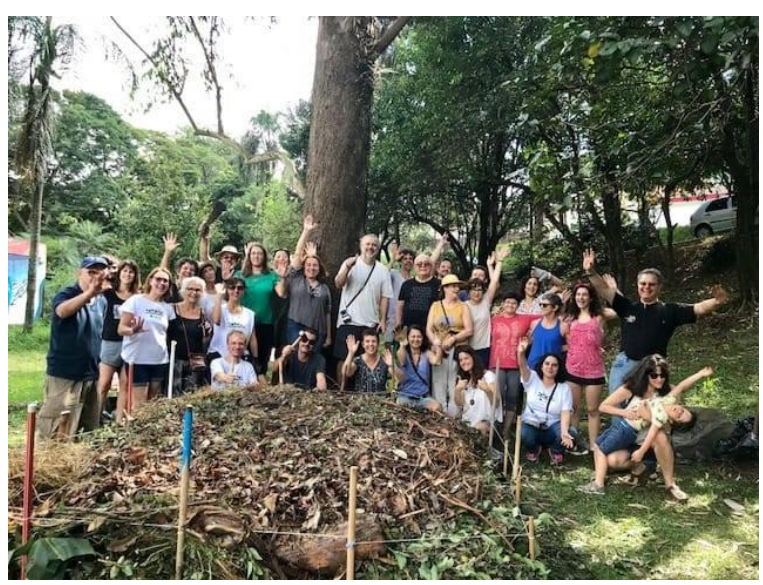

Figura 4: Coletivo das Vilas Beatriz, Ida e Jataí

Outra destinação dada aos restos vegetais da CUASO é o fornecimento de fatias de troncos (bolachas) à comunidade USP, para uso artesanal e confecção de objetos diversos. Apesar de não quantificar esse resíduo doado, o interesse pelo material surgiu ao longo do processo, bem como a importância desse modelo de transformação e reutilização dada ao resíduo.
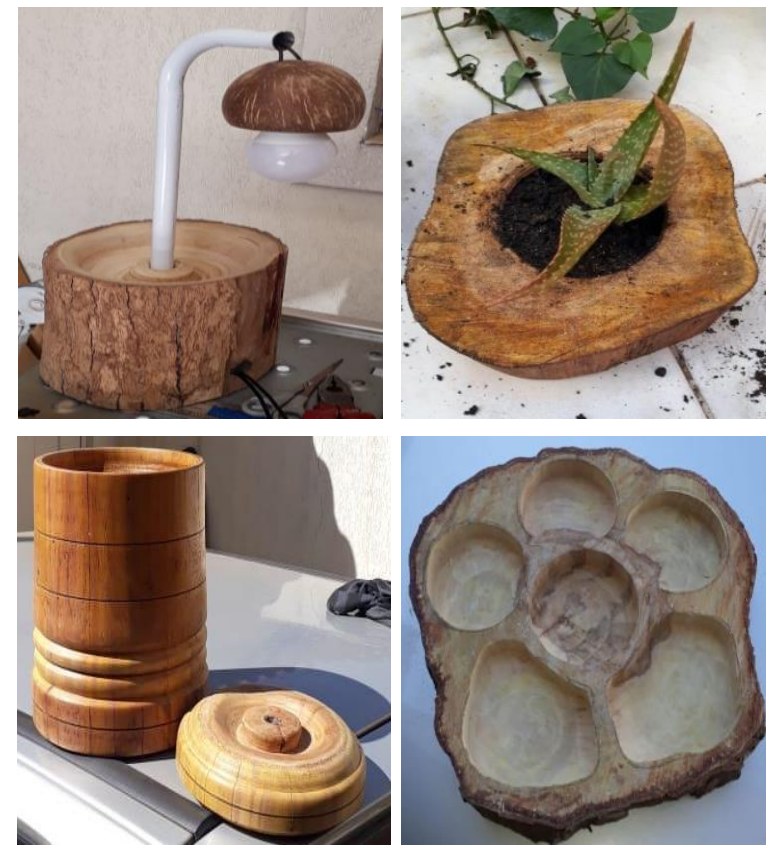

Figura 4: Artefatos confecionados com as fatias de tronco de árvore caída da especíe Tipuana tipu. (Imagens: Ricardo Borzan Mota)

Os pedaços de troncos têm sido utilizados para os mais diversos fins, tais como: jardinagem, em formato de vasos ou de apoio para orquídeas e confecção de objetos de uso doméstico, como 
luminária, pilão, petisqueira, tábua de carne, fruteira etc.

A Figura 4 retrata os resultados dessa iniciativa com alguns artefatos feitos por um funcionário da Superintendência de Prevenção e Proteção Universitária (SPPU), com partes de troncos de árvores caídas na CUASO.

\section{CONCLUSÕES}

Uma das melhorias que visamos é o modelo de reutilização do material de poda com o propósito de estimular a criação de artesanatos, utensílios domésticos e até a fabricação de mobiliários urbanos a serem dispnibilizados nas áreas de integração social da CUASO.

Nesse sentido ainda estão em elaboração os procedimentos que possibilitem, de maneira adequada, o acondicionamento e disponibilização de parte desse material para a Seção de Marcenaria da PUSP-C, para os laboratórios didáticos de design e a comunidade USP, visto ser uma excelente fonte de matéria prima.

Estão sendo revistos e melhorados todos os editais de contratação de empresas para manutenção de áreas verdes da CUASO, e uma das formas de controle e monitoramento da destinação será a obrigatoriedade de entrega de certificados de destinação para fins de compostagem ou geração de energia, garantindo não somente a execução do serviço, mas também o conhecimento dos dados de geração da CUASO.

Conforme citado por Meira (2010), reutilizar é prolongar a vida útil de materias, em sua função original ou adaptada. Criar essa possibilidade de tranformação dos resíduos de poda, fazendo dessa transformação uma forma de arte, não é só reutilizar, mas abrilhantar o valor desse resíduo.

\section{AGRADECIMENTOS}

Agradecemos a todos os funcionários do viveiro de mudas da PUSP-C, que são a base de toda a execuçao do processo, em especial ao Sr. Gedeon Almeida de Jesus; e aos nossos funcionários de apoio administrativo Alexandre José Martins e Daniel Pires Lopes.

Importante agradecer nosso chefe imediato nesses úultimos anos, Eng. Suketeru Nagamine (in memoriam), pela convivência e apoio, e que infelizmente, neste ano nos deixou, mas que, em razão de sua participação no trabalho aqui descrito, merece plenamente ser lembrado com muito carinho.

Agradecemos também ao funcionário da Superintendência de Prevenção e Proteção Universitária (SPPU), Ricardo Borzan Mota, por ter nos cedido as imagens das lindas peças artesanais por ele confeccionadas.

\section{NOTAS}

${ }^{1}$ Gerenciamento de resíduos sólidos: conjunto de ações exercidas, direta ou indiretamente, nas etapas de coleta, transporte, transbordo, tratamento e destinação final ambientalmente adequada dos resíduos sólidos $e$ disposição final ambientalmente adequada dos rejeitos, de acordo com plano municipal de gestão integrada de resíduos sólidos ou com plano de gerenciamento de resíduos sólidos

2 Destinação final ambientalmente adequada: destinação de resíduos que inclui a reutilização, a reciclagem, a compostagem, a recuperação $e$ o aproveitamento energético

${ }^{3}$ Disposição final ambientalmente adequada: distribuição ordenada de rejeitos em aterros, observando normas operacionais específicas de modo a evitar danos ou riscos à saúde pública e à segurança e a minimizar os impactos ambientais adversos;

${ }^{4}$ Gestão integrada de resíduos sólidos: conjunto de ações voltadas para a busca de soluções para os resíduos sólidos, de forma a considerar as dimensões política, econômica, ambiental, cultural e social, com controle social e sob a premissa do desenvolvimento sustentável.

\section{REFERÊNCIAS}

1. Associação Brasileira de Normas Técnicas (2004). NBR ISO 14001: Sistemas de Gestão Ambiental: Diretrizes gerais sobre princípios, sistemas e técnicas de apoio. Rio de Janeiro.

2. Brasil. (2010). Lei no 12.305. Institui a Política Nacional de Resíduos Sólidos; altera a Lei no 9.605, de 12 de fevereiro de 1998; e dá outras providências.

3. Brasil. (2020). Lei 14.026. Atualiza o marco legal do Saneamento Básico.

4. Coletivo das Vilas Beatriz, Ida e Jataí. (25 de agosto de 2020). https://www.facebook.com/VilaJataiAltodePinheiros /photos/a.267913143360070/1435504263267613

5. Made Vila Bioenergia. (25 de agosto de 2020). https://www.multibioenergia.com.br/empresa/

6. Meira, A. M. (2010). Gestão de resíduos da arborização. [Tese de Doutorado, Escola Superior de Agricultura "Luiz de Queiroz].

7. Prefeitura do Campus USP da Capital. (25 de agosto de 2020). http://puspc.usp.br/institucional/missao/

8. São Paulo. (2002). Lei № 13.478. Dispõe sobre a organização do Sistema de Limpeza Urbana do Município de São Paulo. 